\title{
O direito fundamental e coletivo à saúde no contexto da judicialização
}

The fundamental and collective health rights in the context of the judicialization

El derecho fundamental y colectivo a la salud en el contexto de la judicialización

Larissa de Oliveira Domingos ${ }^{1}$

Gabriela Ferreira de Camargos Rosa²

\begin{abstract}
Resumo
Objetivo: analisar a judicialização frente ao direito fundamental e coletivo à saúde, com enfoque nas causas e problemas acarretados pelo excesso de demandas judiciais. Método: breve revisão bibliográfica e método de análise dedutivo, a partir da interação entre o fenômeno da judicialização e a concepção de saúde como direito fundamental e coletivo. Resultados: foram observadas a obstrução do acesso coletivo à saúde em prol da concretização de ações judiciais individuais. Conclusão: a judicialização da saúde gera inúmeros problemas ao Poder Público e prejudica a isonomia e acesso igualitário ao direito em questão.
\end{abstract}

Palavras-chave: Judicialização da saúde. Direito à saúde. Poder judiciário.

\begin{abstract}
Objective: to analyze the judicialization of the fundamental and collective right to health, with a focus on the causes and problems caused by excessive judicial demands. Method: brief bibliographical review and method of deductive analysis, based on the interaction between the phenomena of judicialization and the conception of health as a fundamental and collective right. Results: this study observed an obstruction of collective access to health for the execution of individual lawsuits. Conclusion: the judicialization of health generates numerous problems to the Public Authority and harms the equality and equal access to the right in question.
\end{abstract}

Keywords: Health's Judicialization. Right to health. Judiciary.

\section{Resumen}

Objetivo: analizar la judicialización del derecho fundamental y colectivo a la salud, con un enfoque en las causas y problemas causados por excesivas demandas judiciales. Método: breve revisión bibliográfica y método de análisis deductivo, basado en la interacción entre los fenómenos de la judicialización y la concepción de la salud como un derecho fundamental y colectivo. Resultados: se observó una obstrucción del acceso colectivo a la salud para la ejecución de demandas individuales. Conclusión: la judicialización de la salud genera numerosos problemas al Poder Público y perjudica la igualdad y el acceso igualitario al derecho en cuestión.

Palabras-Ilave: Judicialización de la salud. Derecho a la salud. Poder judicial.

\footnotetext{
${ }_{1}^{1}$ Advogada graduada pela Faculdade de Direito da Universidade Federal de Uberlândia; pós-graduanda em Direito Civil pela Pontifícia Universidade Católica. E-mail: larissadomingos2014@gmail.com

${ }^{2}$ Graduanda em Medicina pela Universidade Federal de Uberlândia.E-mail: gabrielacamargosrosa@outlook.com
} 


\section{Introdução}

A judicialização da saúde é um fenômeno político e jurídico em crescimento desde meados dos anos 2000. É caracterizada pela demanda ao Poder Judiciário para a tutela de direitos atinentes à saúde, ou seja, a judicialização da saúde transfere atribuições do Poder Executivo ao Poder Judiciário, o que pode vir a acarretar inúmeros problemas institucionais.

Por outro lado, a saúde é um direito social de segunda dimensão, garantida pela Constituição Federal no rol das garantias fundamentais, mais precisamente no caput do art. 6‥ A mesma Carta determinou, em seu art. 196, que

a saúde é direito de todos e dever do Estado, garantido medicante políticas sociais e econômicas que visem à redução do risco de doença e de outros agravos e ao acesso universal e igualitário às ações e serviços para sua promoção, proteção e recuperação.(1)

O direito à saúde é um direito fundamental que assegura ao homem o mínimo a sua existência e a sua dignidade e decorre do princípio universal da dignidade da pessoa humana, fundamento de toda sociedade democrática de direito e expresso na Constituição Federal, art. $1^{\circ}$, III.

Todavia, pelo Estado ter o dever pela prestação médica e ambulatorial de forma universal e igualitária, prestada a todos integrantes da sociedade, o direito à saúde é tanto um direito fundamental como coletivo, surgindo um impasse sobre a efetividade da judicialização da saúde, que é o tema central deste estudo.

Nesse contexto, serão analisados os problemas causados pela judicialização aos Poderes Públicos, bem como as tentativas já existentes para a minimização dos danos sofridos pelos entes estatais e pela sociedade como um todo por meio de uma breve revisão bibliográfica associada ao método dedutivo.

Inicialmente serão abordadas características referentes aos direitos fundamentais, dissertando sobre suas principais características, em conformidade com a doutrina majoritária e suas cinco dimensões, com enfoque nos direitos fundamentais de segunda dimensão em que se encontra o direito à saúde. Após, será analisada a saúde como garantia ao princípio da dignidade da pessoa humana e, posteriormente, a saúde como direito coletivo. Posteriormente, será estudado o direito à saúde assegurado pelo Estado por meio do Sistema Único de Saúde (SUS) e os princípios fundamentais atinentes ao sistema, seguido de uma exposição sobre a atuação médica no contexto da judicialização. Por fim, 
será explorado o crescimento da judicialização no Brasil, abordando suas causas e consequências, bem como as medidas tomadas pelo Estado para minimizar seus efeitos sociais e políticos, concluindo que a judicialização afeta e prejudica o direito da coletividade em prol do direito individual.

\section{Metodologia}

Inicialmente, realizou-se um breve levantamento bibliográfico e, para isso, buscou-se na literatura científica os descritores judicialização da saúde, direito fundamental e direito coletivo relacionado à saúde e ética médica em bases de dados como Scielo, PubMed, Google Acadêmico. Além disso, buscamos por normatizações e dados oficiais que corroborassem a discussão da judicialização da saúde.

Posteriormente à leitura, partiu-se para o método dedutivo que se pauta no contínuo questionamento sobre a veracidade das informações, na fragmentação de questões complexas em parcelas menores de análise a fim de produzir a análise de forma gradativa e progressiva e, por fim, a criação de um produto que se propõe a uma abordagem completa e geral da temática trabalhada (2).

A construção do texto se deu a partir do conceito mais amplo do direito fundamental e caminhou para um tema de maior complexidade, isto é, a judicialização da saúde em si. À medida que se construiu a problemática da judicialização, foram expostos os diversos caminhos que cruzam esse tema central e apresentadas propostas de hipóteses de soluções na intenção de contribuir com um tema tão complexo.

\section{Dos Direitos Fundamentais}

\subsection{Características}

Os direitos fundamentais são princípios-base de um Estado Democrático de Direito e asseguram garantias políticas, sociais, individuais, coletivas e jurídicas, de modo a fornecer - mínimo à dignidade da pessoa humana e respeitar fatores inerentes ao seu desenvolvimento e de sua personalidade: "Corresponde assim, por inteiro, a uma concepção de direitos absolutos, que só excepcionalmente se relativizam segundo o critério da lei ou dentro dos limites legais. " (3) 
Possuem características inerentes que os diferem dos demais direitos, de acordo com a doutrina majoritária:

a) universalidade: os direitos fundamentais, tomando como fundamento o princípio da dignidade da pessoa humana, devem tutelar todos os indivíduos, independente de quaisquer fatores como raça, sexo, credo, sexualidade (...), bastando ser sujeito ativo dos direitos fundamentais. Nesse sentido, "não é impróprio afirmar que todas as pessoas são titulares de direitos fundamentais e que a qualidade de ser humano constitui condição suficiente para a titularidade de tantos desses direitos" (4);

b) historicidade: uma vez que os direitos fundamentais se adequam às necessidades da sociedade, são frutos de avanços jurídicos e do desenvolvimento social, histórico e cultural, sendo proclamados e extintos de acordo com fatos existentes em determinadas épocas da história. "Os direitos do homem, por mais fundamentais que sejam, são direitos históricos, ou seja, nascidos em certas circunstâncias, caracterizados por lutas em defesa de novas liberdades contra velhos poderes, e nascidos de modo gradual" (5);

c) indivisibilidade: "os direitos fundamentais formam um sistema harmônico, coerente e indissociável, o que importa na impossibilidade de compartimentalização dos mesmos, seja na tarefa interpretativa, seja na de aplicação às circunstâncias concretas" (6);

d) efetividade: o Poder Público deve buscar formas e meios para que os direitos fundamentais não se restrinjam apenas à utopia, de modo que deve objetivar a efetivação e concretização desses direitos;

e) inviolabilidade: uma vez que os direitos fundamentais são garantias do Estado Democrático de Direito, não podem ser violados ou desrespeitados, de tal forma que as normas infraconstitucionais e os atos da administração pública devem ser elaborados e realizados em conformidade com os direitos fundamentais sob pena de responsabilização;

f) inalienabilidade e irrenunciabilidade: os direitos fundamentais são inalienáveis, indisponíveis, imprescritíveis e intransmissíveis, o que se justifica pelo princípio da dignidade da pessoa humana e torna uma garantia da pessoa que, mesmo em estado de necessidade, terá seu direito assegurado pelo Estado. Todavia, para Novelino (7), há a permissão da autolimitação voluntária, que deverá ser analisada em cada caso concreto. 
g) complementariedade e interdependência: todos os direitos e garantias fundamentais estão vinculados uns aos outros e são interdependentes, e devem ser interpretados conjuntamente;

h) relatividade: uma vez que nenhum direito fundamental é absoluto e se encontram inseridos em um contexto com limites fáticos, sociais e jurídicos, encontra limitações em outros direitos asseverados pela própria Constituição. Tais limitações existem de modo a não prejudicar a efetividade dos direitos tutelados e serem aplicadas de forma proporcional.

Partindo desses pressupostos, se verifica que os direitos fundamentais são garantias de direitos básicos que proporcionam a dignidade da pessoa humana em um Estado Democrático de Direito de tal forma que, independente de quaisquer fatores, terão garantias de uma vida digna.

\subsection{Dimensões dos Direitos Fundamentais}

Os direitos fundamentais, conforme sua característica de historicidade, foram criados e promulgados a partir cada evolução e necessidade social de forma a atualizar e garantir novos direitos que passaram a ser, então, necessários.

A criação progressiva dos direitos fundamentais foi classificada doutrinalmente em dimensões, quais são:

a) direitos fundamentais de primeira dimensão: surgiram na era do lluminismo e Jusnaturalismo, pós revoluções francesa e norte americana, com a concretização do respeito às liberdades individuais. Estabeleceu deveres de caráter negativo ao Estado e direitos civis e políticos às pessoas, nascendo, dentre outros, o direito à propriedade privada:

os direitos de primeira dimensão são os direitos de liberdade, pois são fruto do pensamento liberal burguês, de caráter fortemente individualista, aparecendo como uma esfera limitadora da atuação do Estado, isto é, demarcando uma zona de não-intervenção do Estado nas liberdades do indivíduo. (8)

b) direitos fundamentais de segunda dimensão: versam sobre os direitos sociais, econômicos e culturais. Nessa dimensão, o Estado passou a ter, além dos deveres negativos, deveres positivos que visassem garantir a igualdade material, por meio de leis e políticas públicas que atenuassem a desigualdade social;

c) direitos fundamentais de terceira dimensão: são aqueles nascidos no pós Segunda Guerra Mundial, a partir da necessidade de amparar as nações subdesenvolvidas por meio 
de colaborações das nações mais desenvolvidas e ligados à fraternidade e solidariedade com a tutela aos direitos dos vulneráveis. Surgiram nesse bojo os direitos relacionados ao desenvolvimento, meio ambiente, patrimônios e comunicação, sendo também denominados de direitos transindividuais. A criação da Organização das Nações Unidas e a Organização Internacional do Trabalho são exemplos.

d) direitos fundamentais de quarta dimensão: compreendem os direitos relacionados à globalização política e econômica, como o direito à democracia, direito à informação e ao pluralismo;

e) direitos fundamentais da quinta dimensão: há doutrinadores que asseveram que, são relacionados à evolução tecnológica e cibernética. Todavia, outros doutrinadores (9) asseveram ser o direito à paz.

A classificação do direito à saúde quanto à sua dimensão de origem não está pacificada; enquanto alguns doutrinadores entendem ser inserido na primeira dimensão por ser ligado ao direito à vida, pessoal e independente, outros doutrinam que o direito à saúde pertence aos direitos fundamentais de segunda dimensão por exigirem do Estado uma conduta ativa, por meio de políticas públicas, que assegure a tutela, proteção, concretização da população ao efetivo acesso à saúde, pensamento pelo qual partilhamos e motivo pelo qual a segunda dimensão merece destaque.

Os direitos da segunda geração merecem um exame mais amplo. Dominam o século XX do mesmo modo como os direitos da primeira geração dominaram o século passado. São os direitos sociais, culturais e econômicos bem como os direitos coletivos ou de coletividades, introduzidos no constitucionalismo das distintas formas de Estado social, depois que germinaram por obra de ideologia e da reflexão antiliberal do século XX. Nasceram abraçados ao princípio da igualdade, do qual não se podem separar, pois fazê-lo equivaleria a desmembrá-los da razão de ser que os ampara e estimula. (10)

Os direitos fundamentais de segunda dimensão se consolidaram, em grande parte, a partir das constituições no século XX, decorrentes, notadamente da Revolução Industrial. $O$ aumento significativo da industrialização acarretou grande crescimento demográfico e evolução tecnológica e gerou consequências sociais e econômicas que afetaram a vida de milhares de pessoas, entre elas uma grave desigualdade social que motivou várias manifestações populares por melhores direitos de trabalho e de vida. 
Nesse contexto, nasceram os direitos constitucionais sociais, que têm como objetivo a garantia ao princípio da igualdade material entre os homens pelo direito à saúde, alimentação, moradia, segurança, habitação, previdência, assistência social, educação e trabalho, exigindo uma atuação positiva do Poder Público, por meio de políticas públicas e normas regulamentadoras. Podem ser definidos como os direitos provenientes da necessidade de compensar as desigualdades sociais e econômicas e que objetivam assegurar ao homem o exercício de sua personalidade em consonância com o princípio da dignidade humana.

Com os direitos da segunda dimensão, brotou um pensamento de que tão importante quanto preservar o indivíduo, segundo a definição clássica dos direitos de liberdade, era também despertar a conscientização de proteger a instituição, uma realidade social mais fecunda e aberta à participação e valoração da personalidade humana, que o tradicionalismo da solidão individualista, onde se externara o homem isolado, sem a qualidade de teores axiológicos existenciais, ao qual somente a parte social contempla. (8)

Pode-se afirmar que o Estado, ao agir com uma conduta negativa, enquanto um garantidor dos direitos da primeira dimensão que asseguram ao indivíduo sua liberdade e direitos particulares e, passou a ter igualmente o dever positivo de assegurar tais direitos sociais de segunda dimensão, devendo ser o propulsor da igualdade entre os desiguais, ao garantir à parcela da população mais desprovida o mínimo necessário à existência humana.

Os direitos sociais foram positivados internacionalmente, em 1948, com a Declaração Universal dos Direitos Humanos, que assevera que todo ser humano tem direito a um padrão de vida capaz de assegurar a si e à sua família, dentre outros, a saúde, mencionado em seu art. 25 (11). No Brasil, tais direitos sociais são consagrados pela Constituição Federal de 1988 em seu art. $6^{\circ}$ (1), que assevera que todos têm direito à saúde, sendo dever do Estado prestar o devido auxílio para sua concretização (art. 196).

\section{Princípio da dignidade da pessoa humana}

Os direitos humanos são decorrentes do jusnaturalismo e da noção que alguns dos direitos do homem são inalienáveis e imprescritíveis, de forma que são decorrentes da própria natureza humana. Nesse sentido, os direitos iluministas, que consagram a primeira dimensão dos direitos fundamentais, exaltam a liberdade do homem e seus valores individuais (12). Posteriormente, foi constatado que somente a atuação negativa do Poder 
Público não era o suficiente para assegurar o mínimo de dignidade ao homem, surgindo os direitos e garantias sociais.

Historicamente, foi constatado que as minorias, juntamente com as classes pobres da sociedade, não eram depositárias de direitos, vez que constituíam uma grande parcela da população que era esquecida pelo Estado e não tinham assegurado o mínimo necessário à sua existência.

O reconhecimento e a proteção da dignidade da pessoa humana pelas constituições em diversos países ocidentais tiveram um vertiginoso aumento após a Segunda Guerra Mundial, como forma de reação às práticas ocorridas durante o nazismo e o fascismo e contra o aviltamento desta dignidade praticado pelas ditaduras ao redor do mundo. A escravidão, a tortura e, derradeiramente, as terríveis experiências feitas pelos nazistas com seres humanos, fizeram despertar a consciência sobre a condição de mero objeto. Tempos depois, com a queda do comunismo, a partir do início da década de 1990 , diversos países do leste europeu também passaram a consagrar a dignidade da pessoa humana em seu texto constitucional. (7)

Importante destacar que, durante o lapso temporal entre os direitos fundamentais de primeira e segunda dimensão, ocorreu a Segunda Guerra Mundial, levando milhões de pessoas à morte de, bem como impondo a quebra de direitos; abusos contra a integridade humana; e, principalmente, uma assustadora desigualdade entre os povos. Nesse contexto, internacionalizou-se os direitos humanos com a Declaração Universal dos Direitos Humanos, aprovada em 1948 pela Assembleia Geral das Nações Unidas, que menciona, no preâmbulo, o reconhecimento à dignidade humana e direitos iguais. $O$ art. $1^{\circ}$ garante às pessoas que "todos os seres humanos nascem livres e iguais em dignidade e direitos. São dotados de razão e consciência e devem agir em relação uns aos outros com espírito de fraternidade".

Também como assegurador e propulsor dos direitos humanos, a Constituição Federal brasileira tem como fundamento a dignidade da pessoa humana, em seu art. 1ํ, III, onde assevera ser o homem o principal detentor de direitos de um Estado Democrático de Direito.

Dentre outros direitos sociais que possuem como norteador o princípio da dignidade humana, a Constituição Federal de 1988 trouxe em seu art. 6o o direito à saúde, que, devido a tamanha importância à existência da pessoa, tem uma seção própria e a determinação, no art. 196, de que é direito de todos e sua garantia é dever do Estado, por meio de políticas sociais e econômicas. 
Constata que o direito à saúde é associado ao princípio da dignidade da pessoa humana porque o homem sem saúde é desprovido de felicidade, realização pessoal, é um ser restrito, violado. Não é possuidor de um dos fatores principais necessários à existência.

O direito à saúde é correlato ao próprio direito à vida, o direito supremo do homem. A ausência de saúde gera o caos, o retorno ao estado primitivo da sociedade.

A própria Declaração Universal dos Direitos Humanos trata a saúde como um direito humano fundamental, quando aduz que o homem deve ter um padrão de vida que assegure a si e a sua família saúde e cuidados médicos e serviços sociais e em casos de doença (art. 25):

Art. 25 1. Todo ser humano tem direito a um padrão de vida capaz de assegurar a si e a sua família saúde e bem estar, inclusive alimentação, vestuário, habitação, cuidados médicos e os serviços sociais indispensáveis, e direito à segurança em caso de desemprego, doença, invalidez, viuvez, velhice ou outros casos de perda dos meios de subsistência fora de seu controle (10).

A Constituição Federal brasileira de 1988 assegura o direito à vida como direito fundamental do homem (art. 5º, caput). Não obstante, garante a dignidade da pessoa humana como princípio fundamental do Estado Democrático Brasileiro (art. 1ํ, III) e assegura a todos o direito à saúde, como um direito social (art. 6ํㅜ caput), com o Estado com o dever de ser garantidor desse direito (art. 196) (1).

\section{A saúde como direito coletivo}

Se, por um lado, o direito à saúde é direito fundamental individual que assegura à pessoa sua dignidade e seu direito à vida, por outro, a saúde deve ser um direito garantido de forma igualitária e universal, prestado a todos integrantes da sociedade, sendo caracterizado aqui como um direito difuso, vez que pertence a uma generalidade imensurável, ultrapassando a esfera individual do homem.

Os direitos difusos surgiram em meados de 1970 e são caracterizados pela sua amplitude, podem abranger toda a humanidade ou ater-se ao conceito abstrato do homem. São indivisíveis, se referem a pessoas indeterminadas e possuem como objetivos o bemestar social e, consequentemente, a dignidade humana. Os direitos difusos são caracterizados pela constante mutação, de acordo com as necessidades sociais da época vigente. 
O direito à saúde encontra-se nesse âmbito, amparando todos os indivíduos, necessitados ou não, que demandam por sua integridade física intacta, de tal forma que ultrapassa a seara individual do ser.

No Brasil, o principal marco dos direitos difusos é a promulgação da lei da ação civil pública, regulada pela Lei oํ 7.347/1985, e que, atualmente, em conjunto com o mandado de segurança (art. 5ó, LXIX) é caracterizado por ser um dos principais meios de ingresso de ações judiciais que tem por objeto o direito à saúde. Pode ser impetrado de forma individual, para defender os interesses de uma única pessoa, principalmente quando se trata de doença rara e complexa que exija tratamento individual, ou de forma coletiva, quando várias pessoas buscam o tratamento pela via judicial, por possuírem enfermidades em comum, destacando que, em ambos os casos, o tratamento pleiteado não é abrangido pelo SUS ou advém da demora ao acesso à saúde.

"Tal consideração não determina que as tutelas pela saúde devam ser coletivas necessariamente. Podem ser individuais. Depende do caso concreto. O que não se anui é com a classificação excludente do direito à saúde como direito difuso" (9).

Ante o exposto, podemos concluir que o processo da judicialização da saúde ampara, em sua grande maioria, o direito fundamental e individual do ser que já tem seu direito tutelado pelo Estado quando do fornecimento do tratamento pelo SUS, o que afeta e prejudica, tanto a eficácia das ações coletivas, quanto a concretização da saúde como direitos de todos, no enfoque do direito difuso. $O$ impasse encontra-se presente quando da mensuração do direito fundamental à saúde do ser frente ao direito à saúde da coletividade.

\section{Direito à saúde assegurado pelo Estado através do SUS}

Em consonância com o art. 196 da CRFB e em resposta à necessidade de uma política pública que assegurasse ao ser humano o direito fundamental à saúde, o Congresso Nacional decretou, em 19 de setembro de 1990, a Lei o 8.080 que regula as ações e serviços de saúde em todo território nacional e, em seu art. 4ํㅡㄹ institui o Sistema Único de Saúde (SUS), constituído pelo conjunto de ações e serviços de saúde prestados por órgãos e instituições federais, estaduais e municipais administradas pelo Poder Público (13).

Também em consonância à CRFB, em seu art. 198, que dita as diretrizes organizativas do SUS enquanto uma rede regionalizada, hierarquizada e descentralizada, 
que assegura atendimento integral, priorizando ações preventivas, contudo sem causar prejuízo aos serviços assistenciais e que garante espaço à participação da comunidade, a Lei $n^{0}$ 8.080/90 traz como três princípios fundamentais do SUS:

i) universalidade, que ratifica a saúde enquanto direito que deve ser garantido a todos através de serviços públicos de saúde, independente de características pessoais e sociais, tomando como norteador o princípio da igualdade asseverado pela CRFB;

ii) equidade, que objetiva minimizar as desigualdades ao considerar as vulnerabilidades individuais ou de determinado grupo social historicamente negligenciado, buscando assim, dar iguais condições a indivíduos que são essencialmente desiguais e por isso possuem necessidades distintas.

iii) integralidade, que busca atender todas as necessidades de saúde, extrapolando a assistência exclusivamente terapêutica, ou seja, o tratamento de doenças e fornecimento de medicações, ao também assegurar acesso às ações de promoção de saúde, prevenção de doenças, proteção e recuperação em saúde.

Para tanto, os campos de atuação do SUS abrangem também a execução de ações de vigilância sanitária, epidemiológica e de saúde do trabalhador, bem como a participação na formulação e execução de ações de saneamento básico; formação de recursos humanos na área da saúde; vigilância nutricional; proteção do meio ambiente; formulação de políticas de medicamentos e outros insumos e participação na sua produção; controle e fiscalização de produtos e substância de interesse para saúde; fiscalização de alimentos, água e bebidas para consumo humano; controle e fiscalização da produção, transporte, guarda e utilização de substâncias e produtos psicoativos, tóxicos e radioativos; desenvolvimento científico e tecnológico; e formulação e execução de política de sangue e seus derivados.

Em suma, o SUS compreende a política pública do Estado para garantir a todos os cidadãos brasileiros o acesso à saúde, tanto preventiva quanto terapêutica, enquanto direito fundamental, difuso, universal, integral e equânime.

\section{O profissionalismo médico no contexto da judicialização da saúde}

Diante da complexidade do cuidado em saúde que abrange assistência terapêutica e diagnóstica, prevenção de doenças, promoção de saúde e reabilitação, torna-se necessário grande organização interdisciplinar de enfermeiros, fisioterapeutas, médicos, nutricionistas, 
psicólogos, dentre outros, sendo que a cada um dos profissionais de saúde cabem ações específicas.

A indicação de internação e alta nos serviços de atenção à saúde, indicação e execução de intervenções cirúrgicas, procedimento invasivos diagnósticos ou terapêuticos, bem como prescrição de determinados tipos de medicamentos cabem exclusivamente aos médicos.

Assim, as ações de judicialização em saúde são majoritariamente geradas por indicações médicas, seja realização de um procedimento, obtenção de medicamentos e outros insumos ou necessidade de internação. Além disso, em alguns casos cabe ao médico comunicar ao paciente e/ou aos familiares que determinada necessidade em saúde não está ou não poderá ser adequadamente atendida devido indisponibilidade ou ausência de recursos.

Segundo a ética biomédica principialista, a prática médica é regida por princípios biomédicos, assim, o ato médico deve estar pautado na beneficência, que é a obrigação moral de atuar em benefício à saúde e qualidade de vida do outro, corroborado pelo princípio da não maleficência, que se compromete em não infligir dano ou risco intencional, de modo que, para o exercício da medicina deve-se buscar garantir a instituição de bons métodos diagnósticos, terapêuticos e de cuidados. Entretanto, diante da realidade do sistema de saúde, nem sempre estão acessíveis (14). Além disso, o ato médico deve atuar na promoção e em respeito ao princípio da autonomia dos sujeitos que se refere à capacidade de tomar decisões e agir independente de influências externas que exerçam controle, a partir da compreensão adequada da realidade

Aos profissionais médicos, competem informar adequadamente os pacientes e/ou familiares sobre seu quadro clínico, necessidades de exames complementares, medicamentos ou procedimentos terapêuticos pautados em evidências científicas, bem como prestar esclarecimentos e elucidações, o que, em alguns casos, pode expor necessidades de recursos não disponibilizados, fomentando ações judiciais com objeto saúde.

Ademais, devem prestar assistência de acordo com o princípio da justiça social, que se refere à distribuição igual, equitativa e apropriada de recursos e serviços de saúde. Em concordância com tal princípio, a Carta do Profissionalismo Médico (2002) traz um conjunto 
de responsabilidades profissionais esperadas para o médico do século $\mathrm{XXI}$; ressalta-se 0 compromisso com a distribuição justa de recursos finitos, que se refere à gestão inteligente de recursos, evitando a provisão de despesas desnecessárias e alocando recursos de modo custo-efetivo, bem como o compromisso com a melhoria do acesso ao atendimento para que sejam disponibilizados de forma uniforme e em padrão adequado, buscando reduzir barreiras no acesso e assegurar um sistema de saúde equitativo (15).

Por fim, outra responsabilidade esperada dos profissionais médicos é o compromisso com a melhoria da qualidade dos cuidados, que implica, dentre outras ações, colaborar com outros profissionais para melhorar o cuidado, minimizar o uso excessivo de recursos de saúde e otimizar os resultados dos cuidados (15).

Percebe-se que os profissionais médicos estão direta e indiretamente relacionados à judicialização da saúde, sendo responsáveis por efetivarem a garantia de acesso de forma equânime, bem como o uso correto e racional de recursos e tecnologias em saúde.

\section{A judicialização da saúde}

A judicialização da saúde se iniciou em meados do ano 2000, quando havia alta taxa de portadores do vírus HIV, que pleiteavam no Judiciário o acesso à medicação. Nesse caso, ações individuais somadas, tensionaram o sistema público a reconhecer a demanda de um grupo social e assegurá-los o direito conjunto de acesso ao tratamento antirretroviral por meio da implementação de uma política pública, hoje referência internacional, fazendo cumprir-se os princípios da equidade e universalidade que fundamentam o SUS (16).

Entretanto, observa-se que a judicialização da saúde cresce, no decorrer dos anos, de forma proporcional ao crescimento da expectativa de vida do brasileiro, juntamente com os avanços técnico-farmacêuticos e ampliação dos diferentes fármacos disponibilizados pela indústria-farmacêutica.

Tal fato pode ser comprovado pelo Conselho Nacional de Justiça (CNJ), por meio do relatório Justiça em Números, de 2017 (ano-base de 2016), que demonstrou ter cerca de 1.346.931 processos atinentes à área de saúde em todo o território nacional.

Um estudo multicêntrico, com abrangência nacional, desenvolvido no ano de 2013 , também divulgado pelo $\mathrm{CNJ}$, buscou analisar o cenário da judicialização da saúde e o perfil das demandas apresentadas e suas respectivas respostas (16). 
As demandas apresentadas versavam majoritariamente sobre aspectos terapêuticos em detrimento de aspectos preventivos. Além disso, dois terços das ações sobre medicamentos são referentes a insumos de uso contínuo, tais como fraldas e suplementos nutricionais, os quais utilizam de forma genérica e falaciosa o argumento do direito à vida, banalizando-o e prejudicando os casos emergenciais quando se está realmente em risco.

Igualmente importante mencionar a audiência pública $n^{\circ} 4$, convocada pelo Supremo Tribunal Federal em 2009, que discutiu interdisciplinarmente o problema da judicialização da saúde e o desalinhamento entre as decisões do Judiciário e as posições presentes na audiência.

Nessa audiência pública, o ministro Gilmar Mendes destacou a importância de considerar a existência prévia de uma política pública que abranja a questão em discussão no Judiciário, aumentando assim, a abrangência do rol tratado pelo SUS, pois caso a ação já esteja incluída em alguma política, o Estado estará determinando seu cumprimento.

De acordo o $\mathrm{CNJ}$, grande parte das ações judiciais para pleitear a efetividade das políticas públicas que asseguram o direito à saúde são referentes à tutela de direitos já integrantes do SUS, e decorrem da ausência de efetividade e cumprimento das políticas públicas de acordo ao que foi deliberado pelo Legislativo, o que implica em demora excessiva decorrente da alta demanda ou ausência de orçamento.

Porém, o que se observa do aumento da judicialização da saúde é que tais ações individuais privilegiam parcela da população que detém maior conhecimento dos direitos pertinentes, juntamente com maiores condições de demandar em juízo. Tais ações judiciais geram soluções individuais que não repercutem diretamente nas políticas públicas e não garante o acesso de forma igualitária à saúde, uma vez que a decisão, com efeito inter partes, não assegura a efetividade da política pública ou disponibilidade do tratamento no rol elencado pelo SUS.

Outro problema relacionado à judicialização é o fato que, a partir do momento que o Judiciário avoca as competências dos demais poderes, fere o princípio da separação dos poderes que veda a hierarquia de um Poder sobre o outro e abre caminho para a tomada de decisões referentes a assuntos de competência dos demais poderes e de interesse público, como por exemplo, o direito à moradia, à educação, ao trabalho. 
Entretanto, o orçamento público não é capaz de garantir todas as formas de tratamento a cada cidadão, independente de valores ou circunstâncias. Há, ainda, o fato que não é possível ao poder público estabelecer o quantum a ser gasto com tratamentos provenientes de demandas individuais, uma vez que as ações ajuizadas e decisões são incertas, prejudicando o acesso à saúde pela coletividade em detrimento de um indivíduo isolado, havendo também a distorção de recursos orçamentários e o consequente déficit. Mesmo entendimento segue Chagas e Santos (12).

É fato que a judicialização da saúde é uma situação complexa e que precisa ser problematizada em busca de soluções para não sobrecarregar o Judiciário. Esta garante 0 acesso de vários indivíduos em sua particularidade e individualidade, todavia também gera a desigualdade no acesso à saúde (12).

Sendo assim, os casos de omissões precisam ser encarados como uma demanda conjunta na qual não cabem atitudes ou soluções isoladas, sendo necessária a busca pela efetivação da política pública para que o Judiciário não tenha que intervir no que cabe aos outros poderes e para minimizar $o$ ingresso reiterado no Judiciário e iniquidades provenientes dessas decisões. Nos casos em que o objeto da ação não esteja contemplado dentre as políticas existentes, segundo a audiência pública do STF, deve-se atentar para a possibilidade de substituição por equivalentes já fornecidos pelo SUS em detrimento de opções externas.

Ressalta-se que, na ausência de uma política pública, o processo de judicialização tem papel importante de expor ao Judiciário uma necessidade ainda não atendida e que se opõe ao direito de saúde. Nesses casos, em que há necessidade de inclusão de novas tecnologias, o Estado tem o dever de fornecer acesso a todas e quaisquer tecnologia disponíveis.

Conforme o exposto do art. 19 da Lei ํo 8.080/90 (13), a dispensação de medicamentos e produtos relacionados à saúde deve estar prescrita em conformidade às diretrizes terapêuticas definidas por protocolos clínicos, ou seja, por meio de critérios para diagnóstico bem estabelecidos e conforme tratamento preconizado e posologias recomendadas, com os resultados terapêuticos devidamente comprovados. Quando da falta de protocolo clínico ou diretrizes, deve-se basear nas relações de medicamentos instituídas pelos gestores do SUS no âmbito federal, estadual ou municipal, sendo a responsabilidade 
pelo fornecimento pactuada com a Comissão Intergestores Tripartite, Bipartite ou Conselho Municipal de Saúde, respectivamente.

O registro na Anvisa e comprovação de superioridade são condições necessárias para possível inclusão de um medicamento no rol dos fornecidos pelo SUS, como no caso dos portadores do HIV. A aquisição de insumos em grande escala torna a compra menos onerosa à administração pública do que de forma individual, bem como tem o condão de ampliar a abrangência de pessoas beneficiadas, o que pode acarretar na diminuição da quantidade de demandas individuais.

Em 2016, o CNJ editou a Resolução ํㅜ 238, que dispõe sobre a criação e manutenção, pelos Tribunais de Justiça e Regionais Federais, de Comitês Estaduais da Saúde, bem como a especialização de vara em comarca com mais de uma vara de Fazenda Pública. Tratou-se de mais uma tentativa na busca da redução da Judicialização, e/ou de decisões mais qualificadas.

Tal solução corrobora com a estratégia apregoada na audiência pública do STF que propunha a utilização dos núcleos de assessorias técnicas (NAT), com o propósito de garantir auxílio de profissionais da saúde que conhecem as necessidades e eficácia dos medicamentos e a pertinência de exames aos juízes, assegurando-lhes melhores condições técnicas para tomar decisões. Entretanto, segundo o CNJ (2013), sua utilização ainda permanecia restrita às capitais.

Além disso, faz-se necessário apoio técnico para a revisão periódica dos protocolos clínicos existentes e sua elaboração continuada para suprir a necessidade de acompanhar o surgimento de novas tecnologias e de conhecimento científico. Em outras palavras, ainda são inúmeros os desafios.

Concreto é que a saúde é um direito social que deve ser assegurado a todos, de forma universal, gratuita e integral. Todavia, é igualmente dever do Estado garantir a igualdade de seus cidadãos e prestar políticas públicas de acordo com o princípio da isonomia, de modo que uma pessoa não se prevaleça, em questão de direitos, frente a outra.

\section{Conclusão}

A judicialização da saúde, ainda que possua o objetivo de assegurar os direitos fundamentais à vida, à dignidade humana e à saúde, é prejudicial tanto ao poder judiciário 
quanto à administração pública, pois, de um lado, obstrui o acesso coletivo e universal da saúde de forma igualitária, de outro, torna o gasto orçamentário imprevisível e com destinação individual.

A judicialização excessiva altera as atribuições elencadas na Constituição Federal, uma vez que retira do Poder Executivo a competência de temas correlatos à execução do direito à saúde, e o repassa ao Poder Judiciário.

Todavia, ratifica-se que algumas ações referentes à saúde são necessárias, como por exemplo as inúmeras ações propostas para o tratamento do HIV, como forma de motivar o Estado a atualizar a abrangência do SUS de acordo com as necessidades da população.

\section{Referências}

1. BRASIL. Constituição da República Federativa do Brasil de 1988. Disponível em: http://www.planalto.gov.br/ccivil_03/Constituicao/Constituicao.htm [Acesso em 01.abr. 2019].

2. Borges DM. Método dedutivo, indutivo ou comparativo. Qual o mais adequado à pesquisa do direito internacional do meio ambiente?. Planeta Amazônia: Revista Internacional de Direito Ambiental e Políticas Públicas, n. 6, p. 85-101, 2015.

3. Bonavides P. Curso de Direito Constitucional. Malheiros Editores. 15 Edição, 2004. 4. Mendes GF, Coelho IM, Branco PGG. Curso de Direito Constitucional. 3ª ed. rev. Atual. São Paulo. Saraiva. 2008.

5. Bobbio N. A era dos Direitos. Rio de Janeiro. Editora Campus. 1992.

6. Mansson N. Manual de Direito Constitucional. $4^{\mathrm{a}}$ edição, revisada, ampliada e atualizada. Salvador. Editora JusPodivm. 2016.

7. Novelino M. Direito Constitucional. 6ª ed. rev., atual., ampl. Rio de Janeiro: Forense; São Paulo: Método, 2012.

8. Lurconvite AS. Os direitos fundamentais: suas dimensões e sua incidência na Constituição. Disponível em: http://www.ambitojuridico.com.br/site/index.php?n_link=artigos_leitura_pdf\&\%20artigo_id=4528 [Acesso em 01.abr.2019].

9. Alves CL. A saúde como direito fundamental difuso. Disponível em: http://www.ambitojuridico.com.br/site/index.php?n_link=revista_artigos_leitura\&artigo_id=13091\&revista_cad erno $=9$ [Acesso em 31.out.2018]. 
10. Organização das Nações Unidas. Declaração Universal dos Direitos Humanos. Disponível em: https://nacoesunidas.org/wp-content/uploads/2018/10/DUDH.pdf [Acesso em 01.abr.2019].

11. Lopes AMA. A era dos direitos de Bobbio. Entre a historicidade e a atemporalidade. Disponível em: http://www2.senado.leg.br/bdsf/bitstream/handle/id/242925/000936205.pdf [Acesso em 31.mar.2019].

12. Chagas CP, Santos FP. Efeitos do gasto com a judicialização da saúde no orçamento da Secretaria Estadual de Saúde do Distrito Federal entre 2013 e 2017. Disponível em: https://www.cadernos.prodisa.fiocruz.br/index.php/cadernos/article/view/496/543 [Acesso em 01.abr.2019].

13. Brasil. Lei 8080 de 19 de setembro de 1990. Dispõe sobre as condições para a promoção, proteção e recuperação da saúde, a organização e o funcionamento dos serviços correspondentes e dá outras providências. Disponível em: http://www.planalto.gov.br/ccivil_03/leis/L8080.htm [Acesso em 01.abr.2019].

14. Beauchamp TL, Childress JF. Princípios de Ética Biomédica. Trad.: Luzia Pudenzi. São Paulo: Loyola, 2002.

15. Abim Foundation. American Board of Internal Medicine et al. Medical professionalism in the new millennium: a physician charter. Annals of Internal Medicine, v. 136, n. 3, p. 243, 2002. Disponível em: http://annals.org/aim/fullarticle/474090/medical-professionalism-newmillennium-physician-charter [Acesso em 25.nov.2018].

16. Asensi FD, Pinheiro R. Judicialização da saúde no Brasil: dados e experiência. In: Judicialização da saúde no Brasil: dados e experiência. 2015. Disponível em: http://www.cnj.jus.br/files/conteudo/destaques/arquivo/2015/06/6781486daef02bc6ec8c1e4 91a565006.pdf [Acesso em 04.abr.2019].

Domingos LO, Rosa GFC. O direito fundamental e coletivo à saúde no contexto da judicialização. Cadernos IberoAmericanos de Direito Sanitário. 2019 abr./jun.; 8(2): 82-99. 